\title{
Synthesis and Characterization of Polyethylene Oxide Incorporated with Cadmium Sulphide Nanoparticles
}

\author{
Hind Mohammed Alhusiki-Alghamdi, Naziha Suliman Alghunaim* \\ Department of Physics, Faculty of Science for Girls, King Abdulaziz University, Jeddah, Saudi Arabia \\ Email: ${ }^{*}$ om bushra@yahoo.com, n-al-ghunaim@hotmail.com
}

Received 25 January 2015; accepted 9 February 2015; published 12 February 2015

Copyright (C) 2015 by authors and Scientific Research Publishing Inc.

This work is licensed under the Creative Commons Attribution International License (CC BY). http://creativecommons.org/licenses/by/4.0/

c) (i) Open Access

\begin{abstract}
System of polyethylene oxide (PEO) and PEO incorporated with 2.5 and 5 wt\% of cadmium sulphide (CdS) nanoparticles were synthesized by simple trend chemical techniques and casting method. Characterization and investigation of the samples has been done by different techniques such as: X-ray, UV-visible, photoluminescence (PL) and Transmission Electron Microscope (TEM) techniques. The change of the structural has been interpreted in terms of the structural modifications of the PEO polymeric matrices. The physical properties of nanoparticles were found to relate the size. The crystallite sizes of cadmium sulphide crystals were estimated from the peaks of the $\mathrm{X}$-ray diffraction (XRD) and TEM tools. The average particle size found by TEM is $44 \mathrm{~nm}$. The absorption spectra showed absorption edge at $448 \mathrm{~nm}$ for all the samples. The particle size was estimated by theory and was found to be nearly the same as that obtained by TEM. The optical properties of the samples were estimated by photoluminescence and UV visible spectroscopy.
\end{abstract}

Keywords

PEO, CdS, X-Ray, UV, TEM

\section{Introduction}

Nanoparticles are generally categorized as the class of materials that fall between the molecules and bulk materials with an average size between 1 to $50 \mathrm{~nm}$ [1]. Nanoparticles exhibit physical and chemical properties that are different from either the individual molecules, hence attracting an enormous attention during the past few decades. The change in the property of nanoparticles is driven mainly by two factors namely: 1 ) the increase in the surface area to volume ratio; and 2) change in the electronic structure due to the quantum mechanical effects

*Corresponding author.

How to cite this paper: Alhusiki-Alghamdi, H.M. and Alghunaim, N.S. (2015) Synthesis and Characterization of Polyethylene Oxide Incorporated with Cadmium Sulphide Nanoparticles. Advances in Materials Physics and Chemistry, 5, 53-59.

http://dx.doi.org/10.4236/ampc.2015.52008 
with decreasing particle size [2]. The synthesis of semiconductor nanoparticles in colloidal solutions has attracted many researchers due to their unique optoelectronic properties and quantum confinement effects from the bulk materials [3]-[5]. The potential applications of semiconductors in optical switching, single charge memories, single electron transistors, etc. are most investigated. The physiochemical properties of semiconductors are greatly affected by the consequences of low dimensionality when the radius of the particle is comparable to the Bohr radius of the exciton versus the bulk material. Modification in the electronic levels occurred very strongly due to the limited number of atoms in the particles. Such materials in these regime exhibit novel physical and chemical properties due to the large surface to volume ratio as well as size quantization effect in semiconductor nanoparticles [6] [7]. There are several methods of forming and controlling the size of NPs in liquid phase. Capping agents and surfactants prevent uncontrolled growth and agglomeration of the nanoparticles.

Semiconductor nanoparticles have been used in hybrid solar cells [8]. In particular, cadmium sulphide (CdS) is an excellent photosensitive material and has a direct band-gap $\left(E_{g}\right)$ of $3.42 \mathrm{eV}$. The good match of its energy levels with those of semiconductors makes it a good candidate as electron acceptor coupled with polymer as electron donor to form the active layer in hybrid solar cells [9].

There are several methods to obtain CdS nanoparticles like gas phase reaction (with $\mathrm{H}_{2} \mathrm{~S}$ or sulfur vapor), solvothermal method, solution precipitation, and microwave method [10]-[12].

For solar cell applications, however, it is very important to study how the preparation conditions affect the physicochemical properties of synthesized CdS products, and especially the photovoltaic performance of corresponding hybrid solar cells. The CdS nanoparticles (CdS-n) were synthesized by microwave assisted solution precipitation method with two different sulfur compounds: thioacetamide and thiourea. The structural and optical properties of the obtained products were analyzed and compared. It is found that the former were random distributed hexagonal particles, whereas the latter were almost monodispersed spherical ones.

Polymers that can act as coordination sites for cadmium ion aggregation have protected semiconductor nanoparticles. CdS nanoparticles covered by starch and especially amylose form a wide range of inclusion complexes. Soluble starch added during the synthesis has been used as a capping agent in the synthesis of CdS nanoparticles, resulting in well controlled and uniform particles sizes of cadmium-rich nanoparticles.

Polymer/CdS nanocomposites such as polyvinyl carbazole and CdS/polystyrene have been synthesized using various methods [13]-[15].

The main purpose of the present work is to synthesize and analyze the characterization of the CdS nanoparticles incorporated in polyethylene oxide (PEO). Measurements of the prepared samples were done using different techniques such as: X-ray diffraction; UV-visible spectroscopy; Photoluminescence Spectroscopy (PL); and TEM. The work provides an effective route for the production of CdS nanoparticles which might be used in the fabrication of novel optical solar cell and electronic devices.

\section{Experimental Work}

Polyethylene oxide (PEO) (Aldrich Chemical Company Ltd., UK) of a molecular weight $\mathrm{M}_{\mathrm{w}}=90,000$. Cadmium acetate $\left(\mathrm{Cd}\left(\mathrm{CH}_{3} \mathrm{COO}\right)_{2} \cdot 2 \mathrm{H}_{2} \mathrm{O}\right)$ and thiourea $\left(\mathrm{CS}\left(\mathrm{NH}_{2}\right)_{2}\right)$ obtained from Sigma-Aldrich Company. The films were prepared by adding $\approx$ of $1.2 \mathrm{M}$ cadmium acetate into solution of $\mathrm{PEO}$ solution and continuous stirring for about $6 \mathrm{~h}$ at temperature $\approx 60^{\circ} \mathrm{C}$. The solution was left until a clear one was formed indicating a complete dissolution of cadmium acetate. 2.4 $\mathrm{M}$ of thiourea was added with stirring about $60 \mathrm{~min}$. The color of the final solution was changes from transparent to deep yellow color due to formation of nanomaterial. Three samples were named: pure PEO, 2.5 and 5 wt\% obtained PEO.

The X-ray diffraction scans were carried out using Philips PW 1390 diffractometer $(\lambda=0.1540$ nm, operated at $40 \mathrm{kV}, 10 \mathrm{~mA}$ ) using copper target. UV- visible absorption spectra were measured in the wavelength region of 190 - $1000 \mathrm{~nm}$ using V-570 UV-visible, JASCO, Japan spectrophotometer. Fluorescence spectra recorded at room temperature by a JASCO FP6500 fluorescence spectrophotometer, Japan. Observations of morphology were performed using a JEM-1011 transmission electron microscope (TEM) (JEOL, Japan).

\section{Results and Discussion}

\subsection{X-Ray Diffraction}

The X-ray diffraction (XRD) analysis is very useful to investigate the structure of the polymeric materials and it enables to find out whether a material is crystalline or amorphous. Figure 1 represented X-ray spectra of pure 
PEO. It is clear that two main peaks at $2 \theta=19^{\circ}$ and $23.2^{\circ}$ for pure PEO were observed.

Figure 2 shows X-ray spectra of PEO incorporated with 2.5 and $5 \mathrm{wt} \%$ of CdS. The main peaks at $2 \theta \approx 24.8^{\circ}$, $26.7^{\circ}, 28.4^{\circ}, 44^{\circ}$, and $52.1^{\circ}$ are corresponding to (100), (002), (101), (110) and (112) crystalline planes of CdS [16]-[18]. These peaks can be suggested hexagonal phase of CdS with lattice constants of $\mathrm{a}=4.14 \AA$ and $\mathrm{c}=$ $6.72 \AA$.

The average crystalline size of CdS nanoparticle was estimated using Scherrer's diffraction formula [19]:

$$
D=\frac{k \lambda}{\beta \cos \theta}
$$

where $k=0.91, \lambda=0.1541 \mathrm{~nm}$ and $\beta$ is the half-width of the diffraction. The calculated average values of the crystallite size are $49 \mathrm{~nm}$ and $45 \mathrm{~nm}$ for 2.5 and $5.0 \mathrm{wt} \%$, respectively. The results indicate that the average particle size gradually decreased with increase of CdS content.

\subsection{UV-Visible Spectroscopy}

Figure 3 depicts UV-visible spectra of the prepared films. The onset absorption peaks around $483 \mathrm{~nm}$ which attributed to the transition of $1 S_{e}-1 S_{h}$ of CdS nanoparticles are observed. It is known that as far as semiconductor nanoparticles decrease to the nanosize, the energy band gap is increased. Accordingly, a blue shift took place

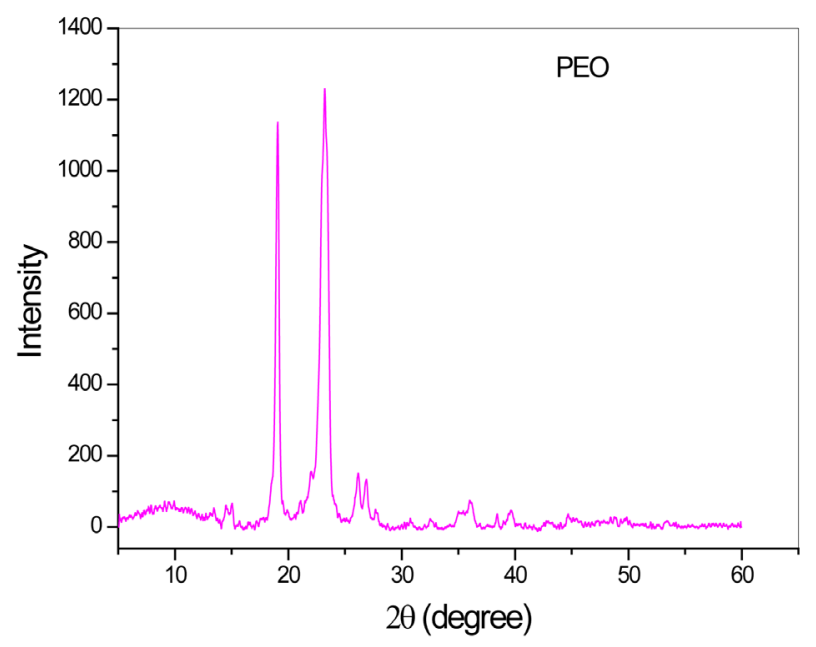

Figure 1. X-ray diffraction spectra of pure PEO.

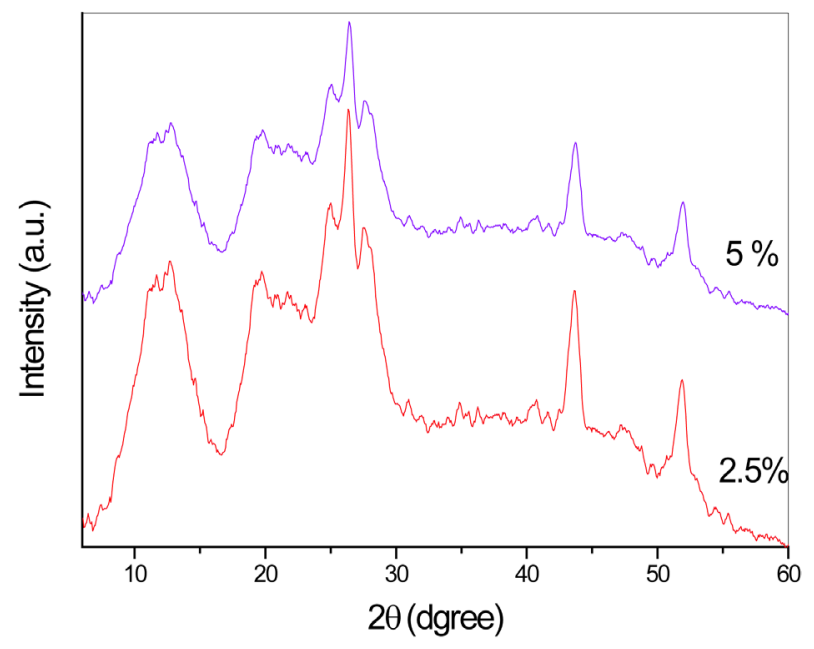

Figure 2. X-ray diffraction spectra of PEO incorporated with CdS. 


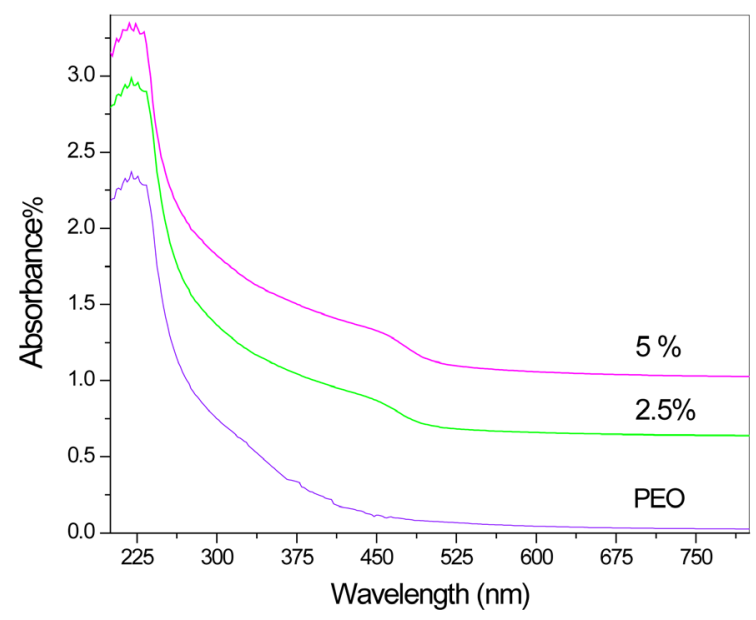

Figure 3. UV-visible spectra for PEO doped with CdS.

which indicates the presence of quantum confinement effect in the UV-visible absorption spectra (The bulk CdS have a peak of about $515 \mathrm{~nm}$ ). The absorption edge is shifted towards the shorter wavelength (blue shift) with decrease in the concentration of $\mathrm{Cd}^{2+}$ ions. This indicates the formation of CdS particles in the polymeric matrix in the nanoscale. Hence, the absorption edge can be used to determine the blue shifted optical energy of the nanoparticles using the relation: $\mathrm{E}_{\mathrm{gn}}=\mathrm{hc} / \lambda$, where $\mathrm{h}$ is the Planck's constant and $\mathrm{c}$ is speed of light.

The optical band gap energy (the energy distance between the valence and conduction bands) is determined by plotting absorption coefficient $\alpha(v)$ as $(\alpha \mathrm{h} v)^{1 / \mathrm{n}}$ versus $\mathrm{h} v$, where $\mathrm{n}$ represents the nature of the transition and $\mathrm{h} v$ is the photon energy. Where $\mathrm{n}$ have values, such as $1 / 2,2,3 / 2$ or 3 for direct, indirect, forbidden direct and forbidden indirect transitions, respectively.

The estimated values of the optical absorption spectra measurement is done using Mott and Davis concept for the direct optical band gap energy for those samples as shown in Figure 4. The band gap energy determined from the extrapolation of the linear section of the curves to $\mathrm{x}$-axis in which $(\alpha \mathrm{h} v)^{2}=0$ [20] [21].

The calculated value of band gap energy decreases following the CdSconcentration from $4.04 \mathrm{eV}$ to $3.32 \mathrm{eV}$ for $2.5 \mathrm{wt} \%$ of CdS and to $2.92 \mathrm{eV}$ for $5 \mathrm{wt} \%$ of CdS which is explained on the basis of the fact that the incorporation of amount of CdS forms charge transfer complexes in the host lattice (polymer matrix) and $\mathrm{Cd}^{2+}$ ions. This attributed to the formation of defects in polymeric matrix. These defects produce the localized states in optical band gap. These overlaps are responsible for decreasing energy band gap when CdS-filler is increased in polymeric matrix.

\subsection{Photoluminescence Analysis (PL)}

The photoluminescence (PL) spectra of the samples were recorded at room temperature as shown in Figure 5. It is observed that, there is no any photoluminescence emission of pure PEO and there is a broad peak at $475 \mathrm{~nm}$ which attributed to number of trap states. Blue shift is seen with a decrease in the intensity associate with larger size of CdS nanoparticles. This trend is due to quantum confined effect of the samples. The emission of this peak is involved the recombination of electrons trapped inside a sulfur vacancy with a hole in the valence band of the CdS nanoparticles [22].

\subsection{TEM Analysis}

Figure 6 depicts TEM micrograph of morphology and distribution of CdS within PEO matrix. It is observed that more single particles which have size $\approx 44 \mathrm{~nm}$ were obtained. Moreover, a higher density particles and tiny clusters with spherical shapes were connected together with uniform distribution of these spheres in PEO matrices.

\section{Conclusion}

The conclusion after synthesis and characterizing of cadmium sulphide (CdS) nanoparticles dispersed within polyethelene oxide (PEO) is all data from the different techniques indicate that the average particle size gradu- 


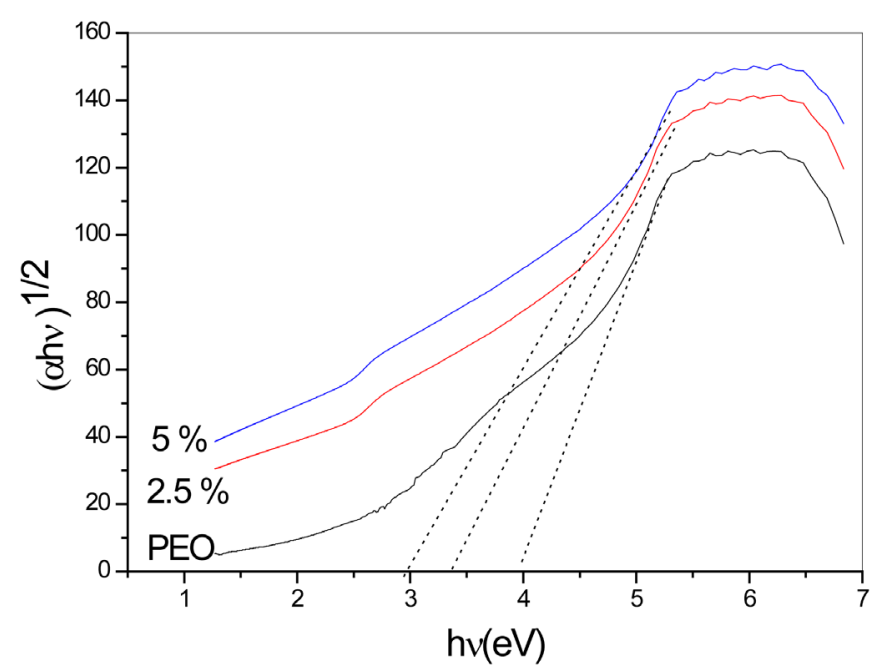

Figure 4. The plots of $(\alpha \mathrm{h} v)^{1 / 2}$ versus hufor PEO blend loaded by 2.5 and $5 \mathrm{Wt} \%$ of CdS.

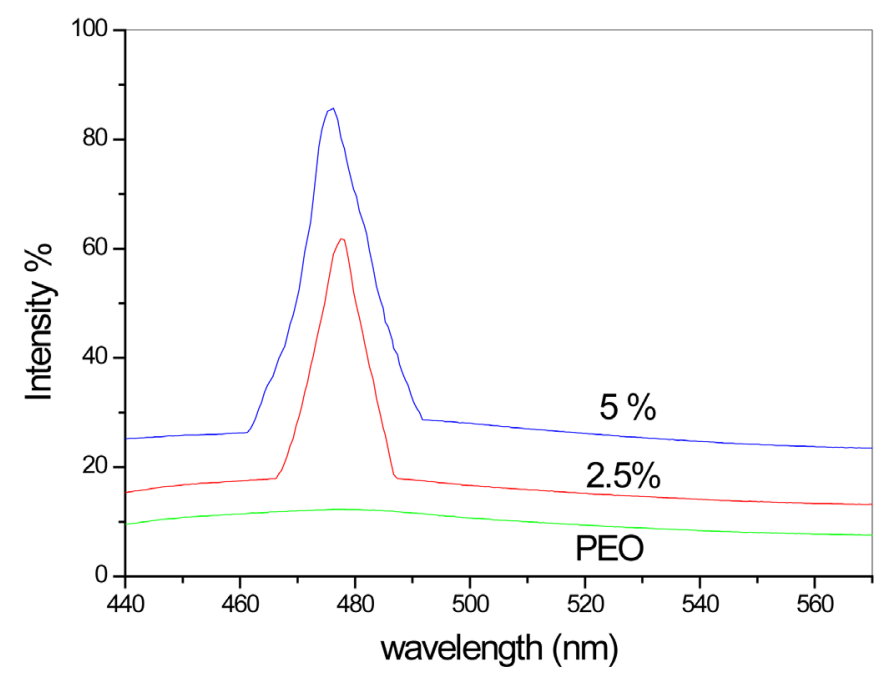

Figure 5. Photoluminescence emission (PL) spectra for PEO with different content of CdS.
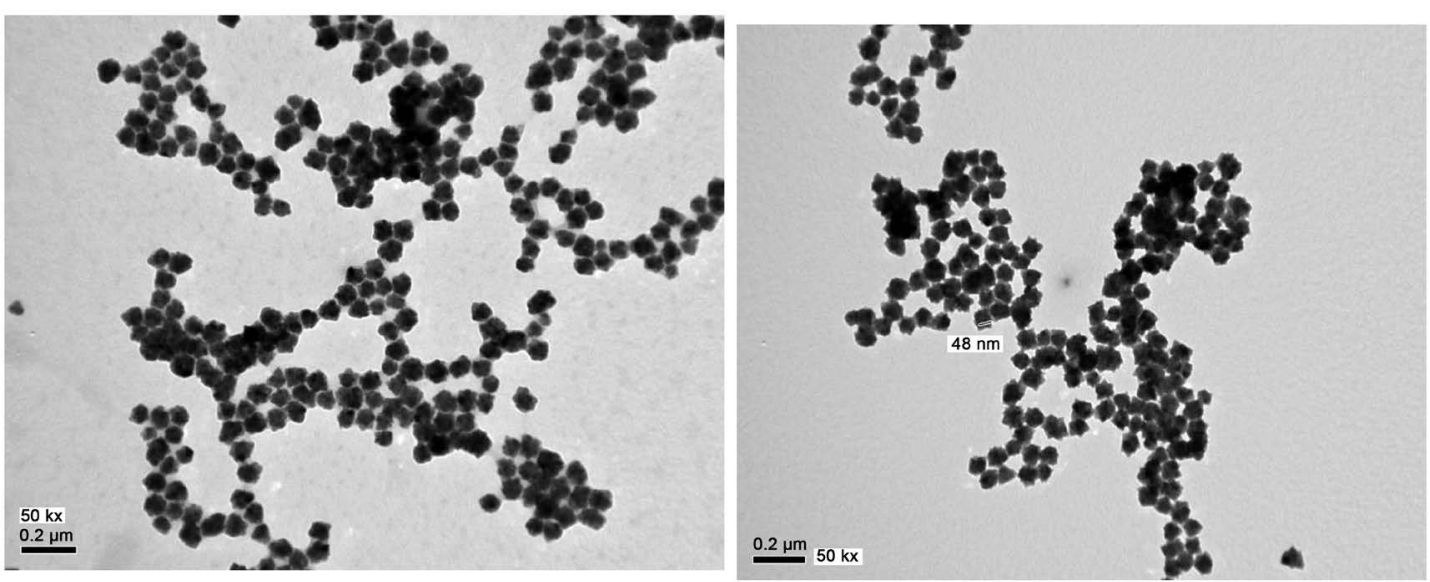

Figure 6. TEM micrograph of morphology and distribution of CdS within PEO matrix. 
ally decreases with increase Cd salt amount. Five peaks in X-ray diffraction are observed, indicating hexagonal phase of CdS. The variation of the band gap and the particle size was attributed to the strong quantum confinement effect of CdS nanoparticles. The photoluminescence (PL) spectra show a broad character of the fluorescence that was attributed to a number of trap states. The blue shift was observed in PL attributed to association with the size of nanoparticles and the complexity of the 3D structures, indicating the quantum confined effect of the nanocomposite films. From the TEM images, the average of particle size is $44 \mathrm{~nm}$ and it decreases with increasing the amount of $\mathrm{Cd}$, which suggests that the particle size is improved with increasing of the amount of CdS content in PEO matrices.

\section{References}

[1] Zang, J.X., Zhao, G.L. and Han, G.R. (2007) Preparation of CdS Nanoparticles by Hydrothermal Method in Microemulsion. Frontiers of Chemistry in China, 2, 98-101. http://dx.doi.org/10.1007/s11458-007-0020-x

[2] Shrivastava, S. and Verma, B. (2007) Preparation and Characterization of Chemically Deposited $\left(\mathrm{Cd}_{0.7}-\mathrm{Zn}_{0.3}\right) \mathrm{S}: \mathrm{CdCl}_{2}, \mathrm{Gd}$ Nanocrystalline Films. Crystal Research and Technology, 42, 466-470. http://dx.doi.org/10.1002/crat.200610849

[3] Ajibade, P.A. and Onwudiwe, D.C. (2013) Optical and Structural Characterization of ZnS, CdS, and HgS Nanoparticles from N-Alkyl-N-Phenyl Dithiocarbamate Complexes. Synthesis and Reactivity in Inorganic, Metal-Organic, and Nano-Metal Chemistry, 43, 10-18. http://dx.doi.org/10.1080/15533174.2012.680129

[4] Tong, H. and Zhu, Y.J.(2006) Synthesis of CdS Nanocrystals Based on Low-Temperature Thermolysis of One SingleSource Organometallic Precursor. Nanotechnology, 17, 845-851. http://dx.doi.org/10.1088/0957-4484/17/3/039

[5] Kulkarni, S.K., Winkler, U., Deshmukh, N., Borse, P.H., Fink, R. and Umbach, E. (2001) Investigations on Chemically Capped CdS, ZnS and ZnCdS Nanoparticles. Applied Surface Science, 169-170, 438-446. http://dx.doi.org/10.1016/S0169-4332(00)00700-5

[6] Marandi, M., Taghavinia, N., Zad, A.I. and Mahdavi, S.M. (2006) Fine Tuning of the Size of CdS Nanoparticles Synthesized by a Photochemical Method. Nanotechnology, 17, 1230-1235. http://dx.doi.org/10.1088/0957-4484/17/5/011

[7] Merkoci, A., Marın, S., Neda, M.T.C., Pumera, M., Ros, J. and Alegret, S. (2006) Crystal and Electrochemical Properties of Water Dispersed CdS Nanocrystals Obtained via Reverse Micelles and Arrested Precipitation. Nanotechnology, 17, 2553-2559. http://dx.doi.org/10.1088/0957-4484/17/10/019

[8] Prabhu, R.R. and Khadar, M.A. (2005) Characterization of Chemically Synthesized CdS Nanoparticles. Pramana: Journal of Physics, 65, 801-807. http://dx.doi.org/10.1007/BF02704078

[9] Lee, H.L., Mohammed, I.A., Belmahi, M., Assouar, M.B., Rinnert, H. and Alnot, M. (2010) Thermal and Optical Properties of CdS Nanoparticles in Thermotropic Liquid Crystal Monomers. Materials, 3, 2069-2086.

[10] Bansal, P., Jaggi, N. and Rohilla, S.K. (2012) Green Synthesis of CdS Nanoparticles and Effect of Capping Agent Concentration on Crystallite Size. Research Journal of Chemical Sciences, 2, 69-71.

[11] Mercy, A., Selvaraj, R.S., Boaz, B.M., Anandhi, A. and Kanagadura, R. (2013) Synthesis, Structural and Optical Characterization of Cadmium Sulphide Nanoparticles. Indian Journal of Pure and Applied Physics, 51, 448-452.

[12] Alonso, C.M., Castaneda, C.A.R., Romero, P.M., Monroy, C.S.C. and Hu, H. (2014) Cadmium Sulfide Nanoparticles Synthesized by Microwave Heating for Hybrid Solar Cell Applications. International Journal of Photoenergy, 1, 1-11. http://dx.doi.org/10.1155/2014/453747

[13] El-Tantawy, F., Abdel-Kader, K.M., Kaneko, F. and Sung, Y.K. (2004) Physical Properties of CdS-Poly(Vinyl Alcohol) Nanoconducting Composite Synthesized by Organosol Techniques and Novel Application Potential. European Polymer Journal, 40, 415-430. http://dx.doi.org/10.1016/j.eurpolymj.2003.10.013

[14] Antolini, F., Pentimalli, M., Di Luccio, T., Terzi, R., Schioppa, M., Re, M., Mirenghi, L. and Tapfer, L. (2005) Structural Characterization of CdS Nanoparticles Grown in Polystyrene Matrix by Thermolytic Synthesis. Materials Letters, 59, 3181-3187. http://dx.doi.org/10.1016/j.matlet.2005.05.047

[15] Kandasamy, K., Singh, H.B. and Kulshreshtha, S.K. (2009) Synthesis and Characterization of CdS and CdSe Nanoparticles Prepared from Novel Intramolecularly Stabilized Single-Source Precursors. Journal of Chemical Sciences, 121, 293-296. http://dx.doi.org/10.1007/s12039-009-0032-9

[16] Vishwakarma, P., Ramrakhiani, M., Singh, P. and Bisen, D.P. (2011) Synthesis and Electroluminescence Studies of Manganese Doped Cadmium Sulfide Nanoparticles. The Open Nanoscience Journal, 5, 34-40. http://dx.doi.org/10.2174/1874140101105010034

[17] Liu, S.H., Qian, X.F., Yin, J., Ma, X.D., Yuan, J.Y. and Zhu, Z.K. (2003) Preparation and Characterization of PolymerCapped CdS Nanocrystals. Journal of Physics and Chemistry of Solids, 64, 455-458.

http://dx.doi.org/10.1016/S0022-3697(02)00333-5 
[18] Chowdhury, S., Ahmed, G.A., Mohanta, D., Dolui, S.K., Avasthi, D.K. and Choudhury, A. (2005) Luminescence Study of Bare and Coated CdS Quantum Dots: Effect of SHI Irradiation and Ageing. Nuclear Instruments and Methods in Physics Research Section B, 240, 690-696. http://dx.doi.org/10.1016/j.nimb.2005.04.127

[19] Ghanbari, D. and Niasari, M.S. (2012) The Effect of CdS/Organic Nanostructure as Additive on the Thermal Stability of ABS Polymer. High Temperature Materials and Processes, 31, 133-138.

[20] Urbach, F. (1953) The Long-Wavelength Edge of Photographic Sensitivity and of the Electronic Absorytion of Solids. Physical Review, 92, 1324-1324. http://dx.doi.org/10.1103/PhysRev.92.1324

[21] Altaf, M. and Chaudhry, M.A. (2005) Effect of $\mathrm{Li}_{2} \mathrm{O}$ on the Refractive Index and Optical Band Gap of Cadmium Phosphate Glasses. Glass Physics and Chemistry, 9, 597-601. http://dx.doi.org/10.1007/s10720-005-0102-0

[22] Wu, C.L. and Zhao, Y.B. (2007) CdS Quantum Dots as Fluorescence Probes for the Sensitive and Selective Detection of Highly Reactive HSe ${ }^{-}$Ions in Aqueous Solution. Analytical and Bioanalytical Chemistry, 388, 717-722. http://dx.doi.org/10.1007/s00216-007-1246-7 
Scientific Research Publishing (SCIRP) is one of the largest Open Access journal publishers. It is currently publishing more than 200 open access, online, peer-reviewed journals covering a wide range of academic disciplines. SCIRP serves the worldwide academic communities and contributes to the progress and application of science with its publication.

Other selected journals from SCIRP are listed as below. Submit your manuscript to us via either submit@scirp.org or Online Submission Portal.
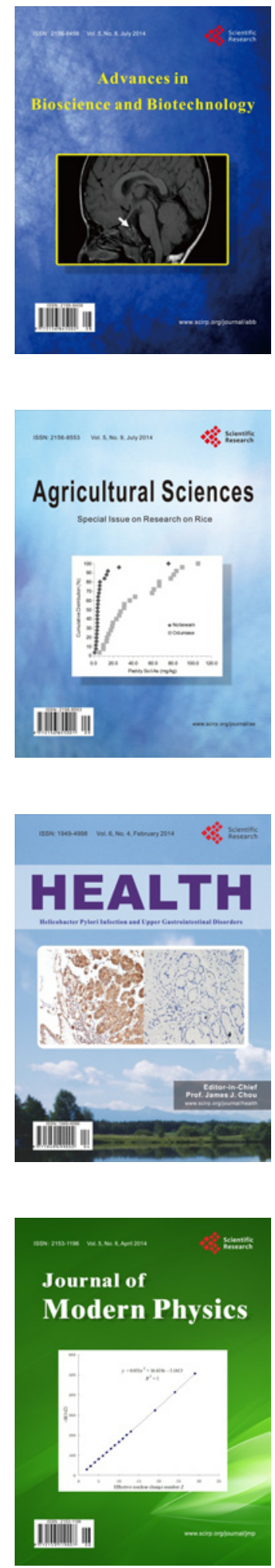
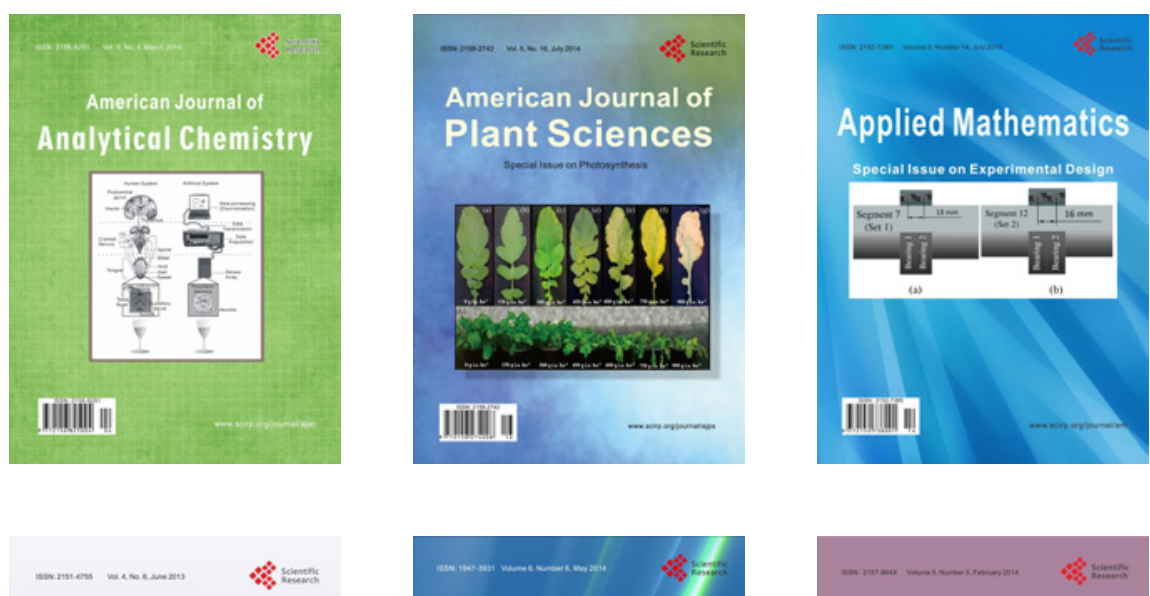

Creative Education
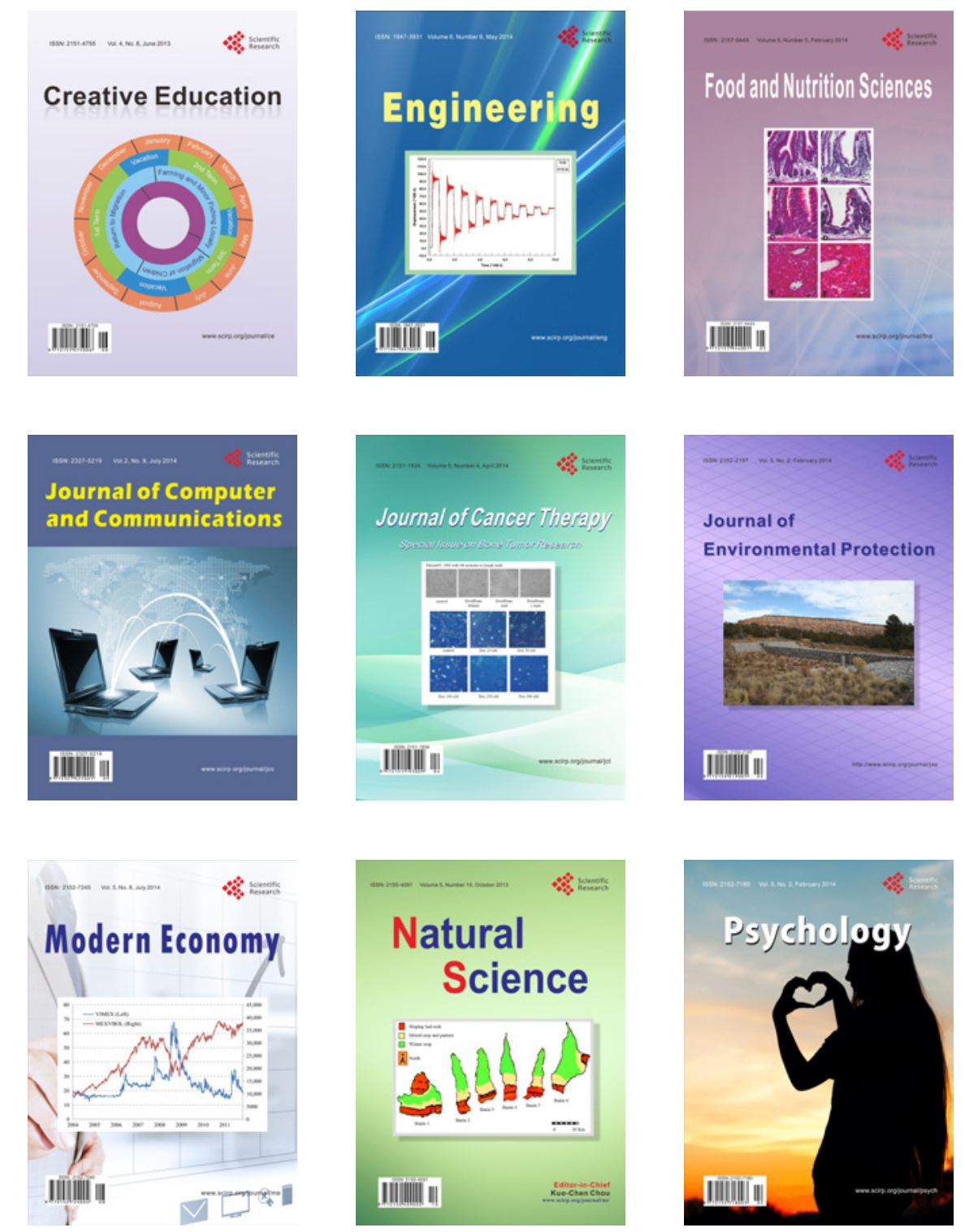